\title{
CONCEPTUAL DESIGN OF TRANSFER MOULD TOOL FOR RUBBER BUMPER SPRING
}

\author{
Akash $\mathbf{N}^{1}$, Hemanth $\mathbf{R}^{\mathbf{2}}$ \\ ${ }^{1}$ Student, Dept. of PG studies, Govt. Tool Room \& Training centre, Mysore, Karnataka, India \\ ${ }^{2}$ Lecturer, Dept. of PG studies, Govt. Tool Room \& Training centre, Mysore, Karnataka, India
}

\begin{abstract}
This paper presents the conceptual design of transfer mould for rubber bumper spring, which is used as housing for auto parts. The fundamental aim of the designer is to achieve balance between productivity and design, by optimizing the design, process and manufacturing parameters, which results in the final cost reduction of the mouldings without compromising the quality of the product. The various parameters like processing temperature, pressure, moulding material, parting line selection, mould cooling, ejection system, etc. affects the design of mould and its functions with variation in cost and quality for producing optimized quality mouldings. By varying some of the above said parameters an effort is made to attain a cost effective conceptual design. The suggested material for rubber bumper spring is NR/BR (Natural \& Polybutadiene Rubber) blend. Designing of mould is carried out by using computer aided designing software solid works 13.
\end{abstract}

Keywords: Transfer mould, NR/BR (Natural and Polybutadiene Rubber) blend, Ejection system $* * *$

\section{INTRODUCTION}

The rubber products manufacturing industry has been growing very rapidly in recent years. This growth will be accelerated by the tendency to substitute rubber for plastics, which is appearing throughout the world. The transfer moulding process is the most popular moulding process for making elastomer parts. The conceptual design of transfer moulding part is a highly iterative process. It involves a practical knowledge about areas of customer needs, part design requirements, material selection, and mold design features, mold making processes, moulding equipment and production economics. The transfer moulding process requires the use of press, raw elastomer material, and a mould [1].

\section{TRANSFER MOULDING}

Moulding is the process of manufacturing by shaping raw material using a rigid frame or model called a pattern [1]. A mold or mould is a hollowed-out block that is filled with a liquid like plastic, glass, metal, or ceramic raw materials. The liquid hardens or sets inside the mold, adopting its shape[1]. Transfer injection moulding is a process where the amount of molding material is measured and inserted before the molding takes place. The molding material is preheated and loaded into a chamber known as the pot. A plunger is then used to force the material from the pot through channels known as a sprue and runner system into the mold cavities. The mold remains closed as the material is inserted and is opened to release the part from the sprue and runner.

The mold walls are heated to a temperature above the melting point of the mold material. This allows a faster flow of material through the cavities [1]. Cost of transfer injection mould is low, high dimensional tolerance can be obtained and little scrap/ waste [1].

- Transfer chamber opened, elastomer inserted

- Transfer chamber closed

- Mould is closed under high pressure

- Removal of the moulded articles, cleaning of the transfer chamber

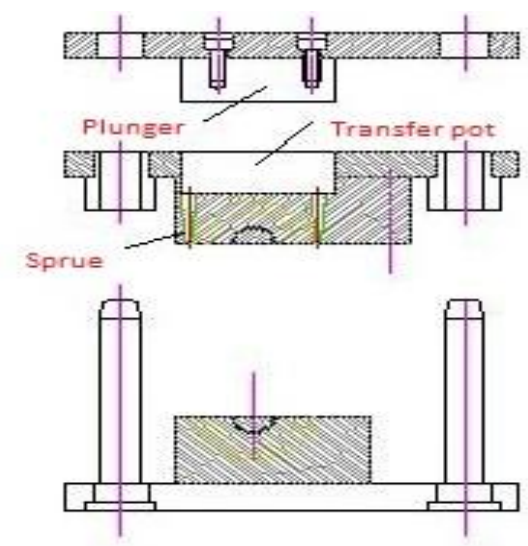

\section{DAY LIGHT DETAILS}

Fig-1: Transfer molding

Factors to be considered during design of any molding tool

- Design and material of components

- Selection of press

- Number of cavities

- Type of tool

- Selection of parting line

- $\quad$ positioning of core and cavity

- Ejection system

- Cooling elements

- Tool life 
All above factors has to be considered during the designing which affects directly or indirectly. In order to control the processing temperature, pressure, melt velocity, filling time, molding material, parting line selection, feed system, mould cooling, ejection system, etc by proper consideration of the factors greater control over the process and process parameters can be obtained.

\section{NR/BR BLEND MATERIAL}

Polybutadiene rubber (BR) is characterized by its superior abrasion resistance, so that blends of NR and BR that combine the excellent processing and physical properties of the former with the superior abrasion resistance of the latter are largely used in the industry in the production of tyre treads and conveyor belts. Natural rubber has a good tensile and tear strength and Polybutadiene rubber has a superior abrasion resistance. By changing the vulcanization temperature from 140-160 degree Celsius, which decreases all the mechanical property like tensile strength and elongation at break by increasing the hardness of the component [2]. Blending of elastomers is widely practised to improve the processing characteristics and physicomechanical properties and to reduce the cost of individual rubbers [3]. Polybutadiene Rubber (BR) has better abrasion resistance than natural rubber (NR), and hence blends of BR and NR are extensively used in the manufacturing process [4]. Under mechanical stress, temperature, moisture, radiations, and aggressive environments, material performances decrease over the time. The alteration of use properties is named "aging" [5]. To reduce the cost and to improve the mechanical properties, thermal aging at ambient temperature has been observed in natural rubber elastomers [6]. Bristow et al. analyzed the changes in properties on NR/BR blends after thermal aging [7], and Mallik et al. studied the thermal aging effect on the physical properties of NR/BR blends at different blending ratios [8]. SaeedTaghvaei et al. studied the Increasing in aging time can affect on rheological, mechanical and thermal properties of cured rubber compounds by thermo gravimetric analysis and rheological measurement [9]. Karak et al. analyzed the hardness of the blends is not much affected by weight fraction of individual component. The results shows the hardness variation of 64-66 shore and BR has lower cure efficiency than NR, since NR contains some basic proteinous substances and also the methyl group in NR enhances the curing process, thus the cure rate steadily decreases with increasing BR content in the blends[10]. The cure characteristics, network structure and vulcanizate properties of 50/50 NR/BR blend. Having conventional curing systems produce a large proportion of polysulphidic crosslinks. This produces a reverting cure in most cases. NR/BR blend of ratio 50/50 have a good curing rate, excellent impermeability, good weather ability [11]. The blend of NR/BR increases the Rheological property, i.e. the study flow of matters in liquid and soft solid state [12].

\section{METHODOLOGY}

Components are modeled using the CAD software Solid Works 2013. Component has a Hallow cylindrical structure with dimensions: Outer diameter $77.3 \mathrm{~mm}$, Inner diameter 27.54 and length $229.5 \mathrm{~mm}$ as a molded part was used. Component has continuous ribs as shown in the figure and other details of model are given below

Component Name: Main body part

Material: NR/BR blend

Shrinkage: $1.7-2 \%$

Moulding type: Single Cavity transfer mould tool

Tonnage required: 100 tonnage capacity

Density: $0.98 \mathrm{~g} / \mathrm{cm} 3$

Projected Area of component: 4208.35 mm2 (From CAD Model)

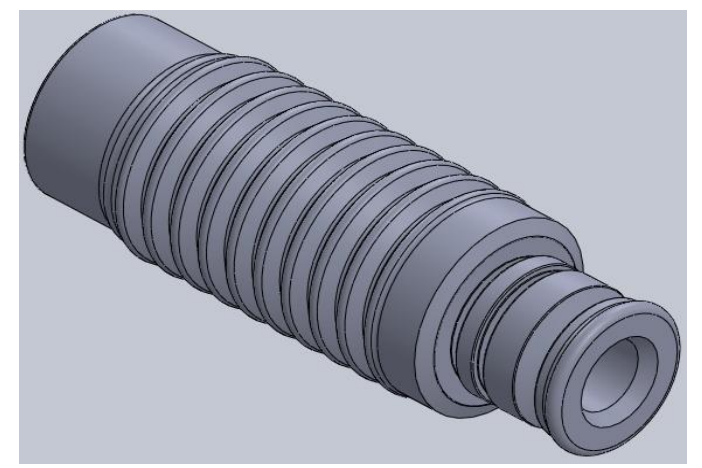

Fig-2: Component 3D model

Hydraulic presses are accepted in many industries because of their wide range of use. They are able to produce significant force, ranging from 10 through 200 tons. Hydraulic presses provide force through the use of fluid pressure on a piston by means of manual or powered pumping element. The power source provides the ability for infinite adjustment of stroke, speed, length and pressure while staying within the limits of press capacity. To carry out the process we are opting for 100 ton hydraulic press of swept volume $482 \mathrm{cc}$ and injection pressure of $1575 \mathrm{~kg} / \mathrm{cm}^{2}$. The molding process includes three significant stages: filling and packing stage, cooling stage, and ejection stage. Among these stages, cooling stage is very important one because it mainly affects the productivity and molding quality. Normally, $70 \%$ 80\% of the molding cycle is taken up by cooling stage. An appropriate cooling channels design can considerably reduce the cooling time and increase the productivity of the molding process. On the other hand, an efficient cooling system which achieves a uniform temperature distribution can minimize the undesired defects that influence the quality of molded part such as hot spots, sink marks, differential shrinkage, and thermal residual stress, so conventional straight drilled cooling system helps to reduce the cycle time of production [13]. The velocity of the cooling water must be high enough to maintain the turbulent flow for cooling the mould. So conventional water jacket's in mould cooling to improve part quality, increase heat transfer rate, and reduce cycle time and maintenance, lower the mould making cost, operating cost. [14], by 
changing the shape and size of the cooling channels help to reduce the heat transfer problem [15].

\section{CORE AND CAVITY}

Core and Cavity are formed when mold is separated into two halves, which permit the part to be extracted. In general the orientation and shape of part must not cause to be blocked into the mold. We are opted for single cavity tool and there is a future scope of multi cavity tool. Fig 3 shows the top half of the cavity which is movable and fig 4 shows the bottom half of the cavity which is fixed. Core 1 and core 2 are adopted and assembled as shown in fig 8. By using two cores we can eliminate side core, which is cost effective.

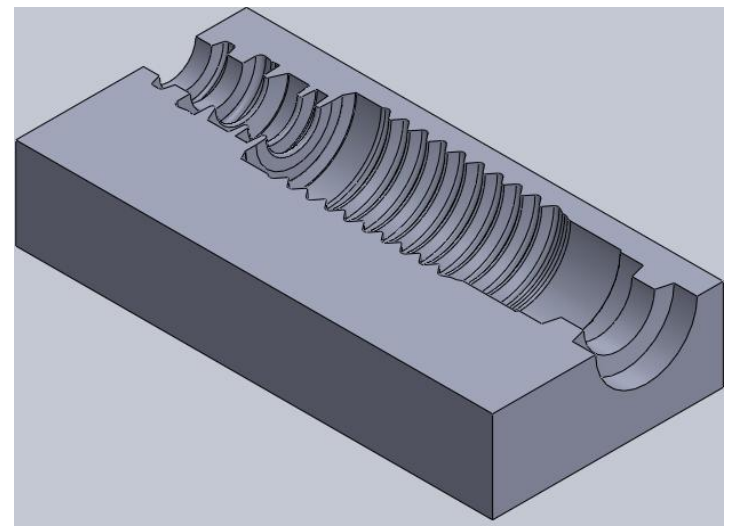

Fig-3: Top half cavity

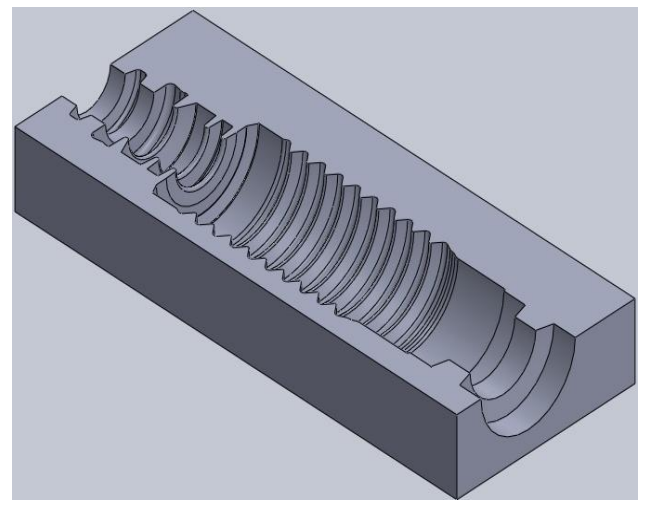

Fig-4: Bottom half cavity

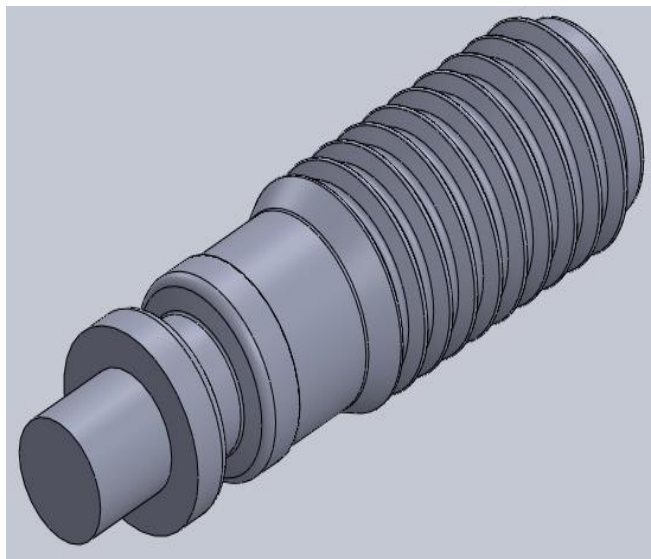

Fig-5: Core 1

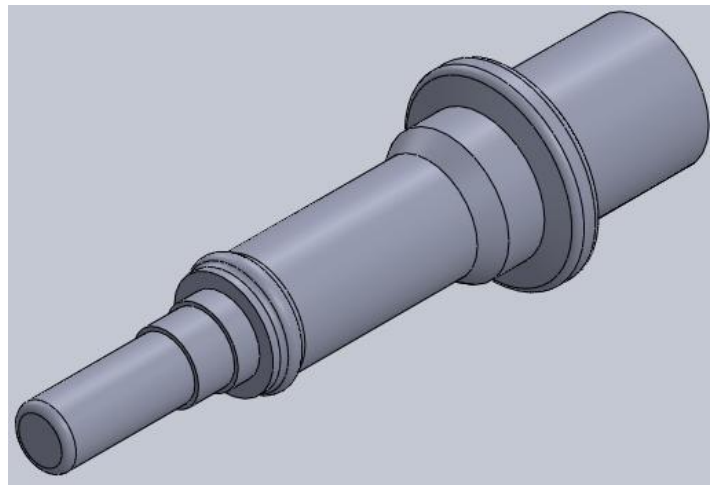

Fig-6: Core 2

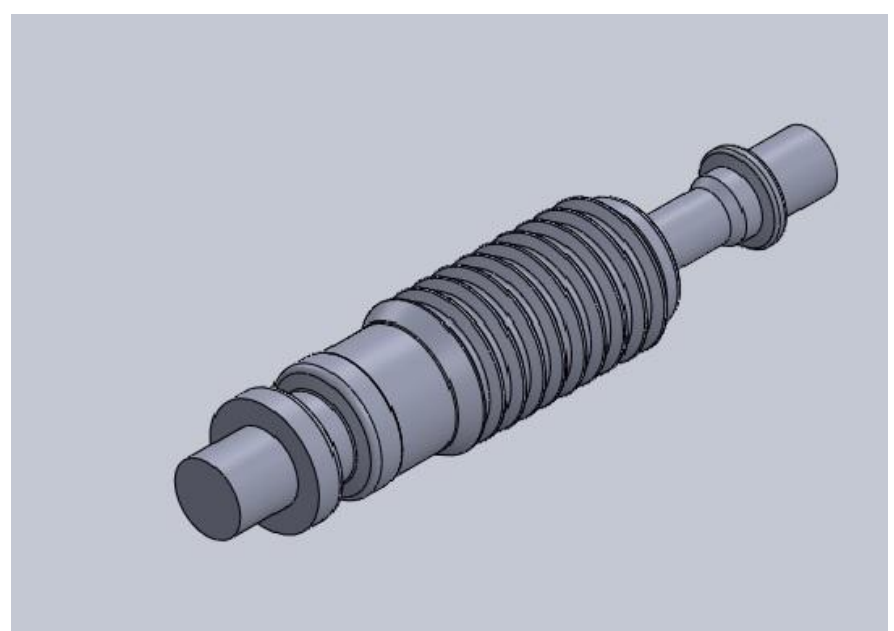

Fig-7: Core assembly

\section{GATE}

A small opening which connects the runner and cavity is called as gate. The gate is of pin point, leaving a very negligible mark on the surface of the component. When designing transfer mold the size and location of the gate is one of the most important considerations for correct moulding of the part. Incorrect gate positioning can result in uneven filling, over packing, and dimensional instability of the part. Incorrect selection of the gate size can result in an inability to fill the part, inability to thermally shut off the gate, dimensional instability or internal stresses in the part.

The most common gate type is direct pin point gating, which offers the simplest construction and high reliability and due to complexity of component design number of gating is provided in each ribs.

\section{EJECTION SYSTEM}

An ejection is very much necessary in order to eject the moulded part from the tool. The design of ejection system is one of the major factors, how efficiently the tool will be in production. The cavity is divided in two mold halves in such a way that natural shrinkage of moulding causes the part to stick moving half when mold open, the core as shown in fig 7 , containing component is taken out of the cavity and dissemble the core as shown in fig 5 and 6 , then air is blow on the other side of the core and the component is removed by dragging out from the core. 


\section{CONCLUSIONS}

The work deals with the Concept of designing of transfer mould tool for rubber bumper spring. Quality product at considerable cost can be achieved by transfer mould tool. By proper supply of temperature and pressure will overcome the effects on the part being produced. 50/50 ratio NR/BR blend gives reasonable mechanical properties. Proper cooling can be achieved by using suitable conventional cooling method.

\section{REFERENCES}

[1] Krell. Production of rubber moulding by injection transfer moulding, volume 195, page 1-19.

[2] D Zaimova, E Bayraktar, D Katundi, Effect of processing condition on the physical, mechanical and viscoelastic properties, volume 50 issue 2, page 8191, February 2012.

[3] L. M. Robeson, Polymer Engineering and Science, 24 (1984) 587.

[4] R.J.Crawford, Plastics and Rubber Engineering Design and Applications (Mechanical-Engineering Publications Ltd, London, 1985) p. 69.

[5] M. Dos Santos, PAZ. Suarez and J. C. Rubim, PolymDegrad Stab 90 (2005) 34.

[6] R. L. Warley and J. Halladay, Polym Test 24 (2005) 678.

[7] G. M. Bristow and C. Metherell, Rubber Ind 7 (1973) 252.

[8] A. K. Mallik and R. D. Shah, Indian Rubber Manufactures' Research Association, Thana (1983) 31-43.

[9] Saeed Taghvaei Ganjalia, FereshtehMotieea, A Study of Aging Properties of Uncured NR/BR Blends: Using TG-DTG Technique, Vol. 2, No. 4, 2011.

[10] N. Karak and B.R. Gupta, Effects of Different Ingredients and Cure Parameters on Physical Properties of a Tyre Tread Compound, vol-2 ,12/2000.

[11] Rani Joseph, George Joseph, Thomas, Studies on the Cure Characteristics and Vulcanizate Properties of 50/50 NR/BR Blend, Vol. 12,1987, pp. 53-64

[12] FereshtehMotiee, SaeedTaghvaei-GanjaliInvestigation of correlation between rheological properties of rubber compounds based on NR/BR rubber with their thermal behaviors, 22 February 2013, doi: 10.1186/2228-5547-4-16.

[13] Hong-Seok Park and Xuan-Phuong Dang. Design and Simulation-Based Optimization of Cooling Channels for Injection Mould, March, 2012, ISBN 978-953-51-0480-3.

[14] Ashish Khare, Amitesh Paul, Tiwari, Design Development Of Test-Rig To Evaluate Of Heat Pipes In Comparison To Conventional Water Jacket's In Mould Cooling, Vol. 2 (1), 2012, 34-43, ISSN No 2249-8303.

[15] Bugarin, Mongeau, Schmidt. 3D BEM-based cooling-channel shape optimization for injection moulding processes, Vol-2, January 2010.

\section{BIOGRAPHIE}

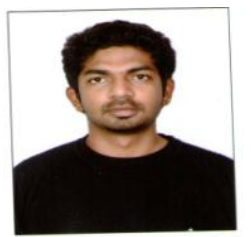

I am Akash N, Doing M.Tech (Tool Engineering) in Government Tool Room and Training Centre, Mysore. Currently doing our final semester project work on Transfer mould Tool Design 